\title{
Society for Social Medicine
}

The thirty fourth Annual Scientific Meeting of the Society was held in Glasgow on September 12-14, 1990, under the presidency of Professor James McEwen. The following papers were presented (arranged in alphabetical order of first author).

A prospective study of cases of fractured neck of femur in three hospitals: case severity, resource use and outcome.

A Backhouse, C Withey, G Bevan, R Morris, P Burney

Department of Public Health Medicine, UMDS, St Thomas's Campus, London SE1, UK

The fetal origins of cardiovascular disease

D J P Barker, C Osmond

MRC Environmental Epidemiology Unit University of Southampton, Southampton, UK

The prevalence of Downs Syndrome in live births among Bangladeshis in East London

I N Basnett

Department of Clinical Epidemiology, The London Hospital Medical College, Turner Street, London E1, UK

Joint and limb symptoms in children following immunisation with mumps, measles and rubella vaccine

C M Benjamin, J E Chew, A J Silman

ARC Epidemiology Research Unit, Stopford

Building (University of Manchester), Oxford Road, Manchester, UK

Mortality and mobidity survey of children with diabetes diagnosed before age 24 months

J L Botha, H Parker, N T Raymond (Dept of Community Health, University of Leicester, Leicester), and P G F Swift (Department of Paediatrics, Leicester General Hospital, Leicester, UK)

Randomised controlled trial of nursing home and hospital care of the elderly Anne Bowling, Juliet Formby

Department of Public Health, City and Hackney Health Authority, St Leonards, Kingsland Road, London N1, UK

How much does the public know about fat intake and heart disease?

Janet Cade, Janice Tate

Community Medicine, South Academic Block, Southampton General Hospital, Southampton, UK

Housing or homelessness: from crisis to crisis

J B Connelly, P Roderick, C Kelleher (MRC Epidemiology and Medical Care Unit, Northwick Park Hospital, Watford Road, Harrow, Middlsex HA1 3UJ), and C Victor (St Mary's Hospital, London W2 1NY, UK)
Health status, health behaviour and employment status in middle-aged British men

D G Cook, J K Morris, A G Shaper

Department of Public Health and Primary Care, Royal Free Hospital School of Medicine, London NW3, UK

Variations in hospital admission rates: the GP as gatekeeper

Angela Coulter, Valerie Seagroatt, Klim McPherson

Unit of Clinical Epidemiology, University of Oxford, Oxford RHA, Old Road, Headington, Oxford; and Department of Public Health and Primary Care, University of Oxford, Gibson Building, Radcliffe Infirmary, Oxford, UK

The body size, shape, and pulse rate of ex-smokers in relation to smokers and non-smokers and time since cessation of smoking

B D Cox, Margaret J Whichelow

University of Cambridge School of Clinical Medicine, Fenner's, Gresham Road, Cambridge, UK

The high prevalence of diabetes in ethnic groups in NW London: an approach to prevention or delay in onset J K Cruickshank

Department of Medicine and Clinical Epidemiology, Northwick Park Hospital, Harrow, UK

Indications for and outcomes of prostatectomy

Helen Doll, Klim McPherson, Jane Davies (University Department of Public Health and Primary Care, Oxford); Nick Black, Maria Ginzler, Mark Petticrew (Department of Public Health and Policy, London School of Hygiene and Tropical Medicine, London WC1); Ann Flood (University Institute of Government and Public Affairs, Illinois, USA); Joe Smith (Department of Urology, Churchill Hospital, Oxford); and Grant Williams (Wimpole Street, London W1)

A methodological inquiry into the general household survey longstanding illness question

Graeme Ford, Sally Wyke

MRC Medical Sociology Unit, 6 Lilybank Gardens, Glasgow, UK

Availability of cadaver organs for transplantation

Stephen Frankel, Margaret Salih (Health Care Evaluation Unit, Department of Epidemiology and Public Health Medicine, Canynge Hall, Whiteladies Road, Bristol, UK), and Ian Harvey, Debra Coupe, Mary Webb (Department of Public Health Medicine, University of Wales College of Medicine, Cathays Park, Cardiff, UK
Childhood leukaemia and fathers at Sellafield: an epidemiological linkage Martin J Gardner

MRC Environmental Epidemiology Unit, (University of Southampton), Southampton General Hospital, Southampton, UK

On the standardisation of mortality and other rates

S L George, I P Nicholl

Department of Public Health Medicine, University of Sheffield Medical School, Beach Hill Road, Sheffield, UK

Temporal-spatial distribution of childhood cancers in Great Britain

E A Gilman, E G Knox, G W Neale, A M Stewart

Cancer Epidemiology Research Unit, Department of Social Medicine, University of Birmingham, Birmingham, UK

Referrals from general practice: evaluation of two initiatives

Jeremy Grimshaw, Ian Russell, Ross Taylor

University of Aberdeen Medical School, Aberdeen, UK

Sexual behaviour and use of condoms by men attending gay bars in Edinburgh and Glasgow

L D Gruer, G S Lule

HIV \& AIDS Resource Centre, Ruchill

Hospital, Glasgow G20 9NB; and Department of Public Health, University of Glasgow, Glasgow, UK

Bladder cancer: treatment and outcome evaluated in two health regions

M C Gulliford, A Petruckevitch, P G J Burney

Department of Public Health Medicine, United Medical and Dental Schools, St Thomas's Campus, London SE1, UK

Reflex anal dilatation: a clinical epidemiological evaluation

Ian Harvey (University of Wales College of Medicine, Temple of Peace, Cathays Park, Cardiff) and Anthony Nowlan (Medical Informatics Group, Department of Computer Science, Manchester University, UK)

Second cancers in relation to treatment for childhood cancer in Britain

M M Hawkins

Childhood Cancer Research Group, 57

Woodstock Road, Oxford, UK

The effects of mother's employment on child health care management Jenny Hewison, Therese Dowswell Department of Psychology, University of Leeds, Leeds, UK 
Risks and benefits of anti-epileptic drug withdrawal: findings from randomised controlled trial

Ann Jacoby (Institute of Social Studies in Medical Care, London) and David Chadwick (Department of Neurosciences, Walton Hospital, Liverpool, UK)

The changing health profile of the elderly

Carol Jagger, Michael Clarke, Susan J

Clarke

Department of Community Health,

University of Leicester, UK

Preschool vision screening

S N Jarvis, $R$ C Tamhne, L Thompson,

$P$ M Francis, J Anderson, A F Colver

Department of Child Health, University of Newcastle upon Tyne; and the Community

Unit, Newcastle Health Authority, Newcastle upon Tyne, UK

Low immunisation uptake rates: parental non-response or information inaccuracy?

S Jefferies, S McShane, J Oerton, R Beardow, C Victor

Department of Public Health, St Mary's

Hospital, London W2, UK

What outcome measures can be used to evaluate the breast screening programme?

Rachel Jewkes, Mark McCarthy

Department of Community Medicine,

University College London, 66-72 Gower

Street, London, WC1, UK

The provision of health services for rheumatic diseases in the European Economic Community

Steven Jones, Alan Silman

Arthritis and Rheumatism Council Epidemiology Research Unit, Manchester, UK

Beyond the Forrest: the impact of introducing the National Breast Screening Programme on hospital services

Jia Kani, Gualtiero Ricciardi, Grace Tan Health Services Research Unit, Department of Public Health and Policy, London School of Hygiene and Tropical Medicine, Keppel Street, London WCI, UK

Exercise patterns in men and women at 36 years: early life determinants and associated health behaviours

D L Kuh

MRC National Survey of Health and Development, University College London; and The Middlesex Hospital Medical School, Department of Community Medicine, Gower Street, London WC1, UK

Sex differences in the secular trend in height in Britain

D L Kuh, B Rodgers (MRC National Survey of Health and Development, University College London, and the Middlesex Hospital Medical School, Department of Community Medicine, Gower Street, London WC1), and C Power (Social Statistics Research Unit, City University, Northampton Square, London EC1, UK)
Area, class and health: a comparison of two urban localities in the west of Scotland

Sally Macintyre, Sheila MacIver

MRC Medical Sociology Unit, Glasgow, UK

HIV drug injecting and female prostitution in Glasgow

Neil McKeganey, Marina Barnard, Alastair Leyland

Social Paediatric and Obstetric Research

Unit, University of Glasgow, 1 Lillybank

Gardens, Glasgow, UK

What do junior doctors do at night? M McKee, $P$ Priest, $M$ Ginzler, $\mathbf{N}$ Black Health Services Research Unit, London School of Hygiene and Tropical Medicine, Keppel Street, London WC1, UK

Effects of patient, physician and practice setting characteristics on CDM: results of a factorial experiment J McKinlay

New England Research Institute, Watertown, MA 02172, USA

Methodological problems in small area analysis of health status and outcomes with census based variables P McLoone

Social Paediatric and Obstetric Research Unit, University of Glasgow, UK

A new undergraduate curriculum in Health and Disease

Klim McPherson

Department of Public Health and Primary Care, Oxford University, Oxford, UK

Clinical comparison of extracorporeal shock wave lithotripsy (ESWL) and percutaneous nephrolithotomy (PCN) in the treatment of renal calculi: results one and two year follow up

N B Mays, A Petruckevitch, M Buck, P G J Burney

Department of Public Health Medicine United Medical and Dental Schools, S Thomas's Campus, London SE1, UK

Cervical abnormalities. Changing progression rates?

Ruairidh Milne, Margaret Wolfendale, Klim McPherson

Department of Public Health and Primary Care, Oxford University \& Aylesbury Cytology Clinic, UK

Consultation rates in general practice over a 3 year period

J Morris, D G Cook, M Walker, A G Shaper

Department of Public Health and Primary Care, Royal Free Hospital School of Medicine, London NW3, UK

A study into the cost-effectiveness of treatment for colorectal cancer

L Mountney, H Sanderson, J Kirby

Wessex Cancer Intelligence Unit, Royal South Hants Hospital, Southampton, UK

Variations in outcome of different levels of care in pregnancy and the neonatal period-a population based study Lesley Mutch, Colin Pritchard, Anna McGee, Alastair Leyland

Social Paediatric and Obstetric Research Unit, University of Glasgow, Glasgow, UK
An evaluation of minor surgery in general practice and its impact on hospital waiting times

A O'Cathain, $M$ Fall, $P$ Milner, J E Brazier

Medical Care Research Unit, Department of Public Health Medicine, University of Sheffield Medical School, Beech Hill Road, Sheffield, UK

Concurrent use of tobacco, alcohol and caffeine in pregnancy and the effect on birthweight

J L Peacock, J M Bland, H R Anderson Department of Public Health Sciences, St George's Hospital Medical School, London SW17, UK

Myalgic encephalomyelitis and the stigma of mental illness

A J Pelosi

University Department of Psychiatry, Royal Edinburgh Hospital, Morningside Park, Edinburgh, UK

Subclinical deficits of motor and cognitive function in low birthweight infants

P $O$ D Pharoah, R W I Cooke

Departments of Public Health and Child Health, University of Liverpool, PO Box 147 Liverpool, UK

Patterns of risk of delivery during the period 20 to 35 completed weeks of gestation

R M Pickering

Department of Medical Statistics and Computing, University of Southampton South Academic Block, Southampton General Hospital, Southampton, UK

How important is health behaviour to the health of women of lower socioeconomic status?

R M Pill, M R Robling, T J Peters

Departments of General Practice, and Medical Computing and Statistics, University of Wales College of Medicine, Cardiff, UK

Mature maternity: long-term associations in children born to older mothers

J I Pollock

Department of Child Health, University of Bristol, Bristol, UK

Whatever happened to Mrs G-the costs of waiting for surgery

Catherine Pope, Jenny Roberts

Health Services Research Unit, Department of Public Health and Policy, London School of Hygiene and Tropical Medicine, London WC1, UK

Health and deprivation in rural areas R F Reading, P Phillimore

Northumberland Health Authority and Centre for Urban and Regional Development Studies, University of Newcastle, Newcastle upon Tyne, UK

Susceptibility and resilience to psychiatric disorder

$B$ Rodgers

MRC National Survey of Health and Development, University College London and The Middlesex Hospital Medical School Department of Community Medicine, Gower Street, London WC1, UK 
Comparing perinatal mortality in small samples

D Russell, I T Russell, A Wilcox

Department of Community Medicine, University of Aberdeen, UK and The US National Institute of Environmental Health Sciences

Helicobacter Pylori and gastric cancer F Siats, D Forman, et al

Imperial Cancer Research Fund, Gibson Building, Radcliffe Infirmary, Oxford, UK

Socioeconomic differentials in cancer in men

George Davey Smith, David Leon, Martin J Shipley, Geoffrey Rose

Department of Epidemiology and Population Sciences, London School of Hygiene and Tropical Medicine, Keppel Street, London WCl, UK

Socioeconomic factors, menopause, and coronary heart disease risk factors

George Davey Smith (Department of Epidemiology nad Population Sciences, London School of Hygiene and Tropical Medicine, Keppel Street, London WC1) and M G Marmot, E J Brunner, Mandy Feeney, Ian White (Department of Community Medicine, University College and Middlesex Hospital Medical School, Gower Street, London WC1, UK)
Relationship of the rate of use of general health examinations by adults to the use of inpatient services by the elderly in a nationwide survey in Japan

K Tatara, F Shinsho, M Suzuki, T Takatorige, N Nakanishi, K Kuroda Department of Public Health, Osaka University Medical School, Osaka, Japan

Non-orthodox health care use: substitute or supplement? K J Thomas

Department of Public Health Medicine, University of Sheffield, Sheffield, UK

Children and accidents: a survey of exposure to accident risk among schoolchildren

E M L Towner, S N Jarvis, S S M Walsh, R C Waugh

Department of Child Health, University of Newcastle upon Tyne, Newcastle upon Tyne, UK

A future for the Community Nurse practitioner?

Mary Walker

Department of Public Health and Primary Care, Royal Free Hospital School of Medicine, London NW3, UK
Road traffic accidents in childhood

S S M Walsh, S N Jarvis (Department of Child Health, University of Newcastle upon Tyne); W Clarke (Northumbria Police Authority); and S Raybould (North East Regional Research Laboratory, Centre for Urban and Regional Development, University of Newcastle upon Tyne, Newcastle upon Tyne, UK)

Self assessment of health status and mortality in middle aged British men G Wannamethee, A G Shaper

Department of Public Health and Primary Care, Royal Free Hospital School of Medicine, London NW3, UK

Diets of primary school children in nine British towns

P H Whincup, O Papacosta, D G Cook Department of Public Health and Primary Care, Royal Free Hospital and School of Medicine, London NW3, UK

Health and employment status in late middle age: evidence from the west of Scotland twenty -07 study

Sally Wyke, Graeme Ford

MRC Medical Sociology Unit, 6 Lillybank Gardens, Glasgow, UK

\section{BOOK REVIEWS}

Health and Lifestyles. Mildred Blaxter (Pp 268; £12.95) Tavistock/Routledge, 1990. ISBN 0-415-00147-I.

Based on the Health and Lifestyle Survey, this is a large national survey of some 9000 adults in England, Wales, and Scotland carried out in $1984 / 5$ by a multidisciplinary team (containing, among others, a physiologist, a nutritionist, a psychologist, a sports scientist, and a sociologist) based in Cambridge. The survey was funded by the Health Promotion Research Trust, which in 1987 published a preliminary descriptive report of the main findings. Data from the survey have been lodged in the ESRC Survey Archive and are available to researchers.

In this book Mildred Blaxter reports on an analysis which pulls together a large number of variables into summary indices of concepts such as "health", "social circumstances", and "lifestyles", in order to examine the relative importance for people's health of social circumstances and more "voluntary" health related behaviours. This is an ambitious project, as the author admits at the beginning. In focusing on general determinants of health in the population, rather than on the aetiology of specific disorders or the health of particular groups, this is, however, an important and unusual task well worth undertaking.

As always Mildred Blaxter writes well and directly, and she spells out clearly the reasoning underlying the strategy of analysis and interpretation of results. A wealth of material is presented in some detail in the book, however, and therefore despite the lucidity of the author's style it is possible for the reader to get bogged down in the data. It is not a book to be read quickly in a single sitting in order to get an overview of the topic or analysis, but rather one to be selectively reread in order to derive maximum benefit from the presentation of detailed data and arguments on specific topics.

Blaxter must be one of the few researchers brave enough (and competent enough) to collect and analyse verbatim responses to open ended questions addressed to a sample of 9000 . Her fascinating use of the resulting data in a chapter on concepts of health vindicates this unusual use of open ended questions in large scale survey research, and shows that the analysis of these sorts of rich data need not be confined to small scale or less representative research

The analysis proceeds first by constructing summary indicators and describing their distribution. These cover health (divided into fitness, disease, illness, and pychosocia health: chapter 4); social circumstances (social class, occupation, income, region, type of area, employment, housing etc: chapter 5) behaviours (smoking, alcohol consumption, diet, and exercise: chapter 6); and health related knowledge and attitudes (chapter 7 ) Various univariate analyses are then presented; for example the relationship between income and fitness, social class and smoking, or health related attitudes and exercise. Finally, the results of multivariate analyses are presented.

The conclusion from the closely argued analysis is that "circumstances"-not only socioeconomic circumstances and the external environment, but also the individual's psychosocial environmentcarry rather more weight, as determinants of health, than healthy or unhealthy behaviours. There is no doubt that the four behaviours examined, and in particular smoking, are relevant to health. They have most effect, however, when the social environment is good: rather less, if it is already unhealthy. Unhealthy behaviour does not reinforce disadvantage to the same extent as healthy behaviour increases advantage" (p233). This is an extremely important conclusion with fascinating implications. The finding of an interaction between social circumstances and health related behaviours in their impact on health is interesting, as is the particular form this interaction takes; one might, for example, have hypothesised the reverse process, ie, that unhealthy behaviours have greatest effects among those already socially disadvantaged.

Doubtless some may dispute certain aspects of the analysis, or the interpretation of the results. What should not be doubted however is the importance of the questions being addressed, nor the usefulness of undertaking this type of analysis on such a large sample. Mildred Blaxter is to be congratulated for taking on this fascinating but difficult analysis.

This book should stimulate further research and thinking about general determinants of health in the population, and among different subgroups in the population, and can be highly recommended as a thought provoking and sometimes surprising read.

SALLY MACINTYRE MRC Medical Sociology Unit Glasgow 